\title{
Research on Educational Value of Music Education Based on Multiple Intelligences
}

\author{
Ji Yonghui \\ baicheng vocational \& technical college Jilin, China 137000 \\ Sino1980@163.com
}

\section{Keywords: Educational Value, Music Education, Multiple Intelligences}

\begin{abstract}
Education music education value, for a long time is not easy for people to understand. Multiple structure theory of contemporary American psychologist Gardner for us to explore and examine the value of music education in educating people to provide a new perspective. The theory that human intelligence is not a single, but diverse, including verbal - linguistic intelligence, logical mathematical intelligence and other nine kinds of intelligence. Educational value of music education is not only reflected in the development of music - rhythm on intelligence, it is not only reflected in the people who engage in professional music, but also in the development of other intelligent and smart music and music-related, the embodied in other undertakings in the owner of the body.
\end{abstract}

\section{Introduction}

For our current practice of quality education in the process, there are some misconceptions people implementations of quality education. One of the most representative of the understanding is that the quality of education is widely believed Dezhitimei both education. In fact, the quality of education is not the case, in the process of teaching carried out in the so-called quality education should in fact be the traditional, old teaching paradigm shift over education in order to further improve students' comprehensive abilities undertaken. Thus, the quality of education is based on students' needs and basic social needs of the people as to facilitate their development toward a better direction, the students will be inspired by the potential of efficient, improve the student's personality. Thus, the quality of education is to comprehensively improve the overall quality of students is fundamental. Music is an important part of quality education, educators in the process of educational activities and the music plays an important role.

Awareness of the value of music education, music education in relation to school education should be what is the status of the problem and, therefore, directly related to the problem of survival and development of music education. Based on this, the majority of music educators in exploring this issue has been making unremitting efforts and achieved many thoughtful results. Traditionally understood the value of music education is mainly reflected in the secondary Germany, puzzle, three aspects of fitness, to "nine-year compulsory education music curriculum standards" (trial version) summarized the value of aesthetic experience, creative development of the value of social interaction four values, cultural heritage values, etc., to the value of music education in the most profound Ramo proposed reflected in the "rich sensory experience by improving the quality of life" ([US] Reimer of "Philosophy of Music Education"), you can He said people awareness of the value of music education has gradually become a comprehensive, scientific, profound. But it should be admitted that so far we have stated all the value of music education or a more abstract and difficult to understand, or somewhat iffy and hard to convince people. Why is this? An important reason is probably one of our understanding of the value of music education is not based on advanced scientific and theoretical basis.

We believe that in order to truly scientific, fully grasp the value of music education, music education must start from connotation, that must be the connotation of music education in music education as we explore the value of the logical starting point. 


\section{The Value Embodiment of Music Education Educational Role}

American psychologist Gardner from the 1970s began to study the structure theory of multiple intelligences, after decades of research to explore its theory can not only provide a theoretical basis for quality education, but can also educate people value music education provides a theoretical basis. Structure theory of multiple intelligences Gardner believes that intelligence is not a single individual, but rather diverse, including a total of nine areas: verbal / linguistic intelligence, logical / mathematical intelligence, visual / spatial intelligence, musical / rhythmic intelligence, bodily / kinesthetic intelligence, interpersonal intelligence, self-reflection smart, intelligent observer of nature, the presence of intelligence. He also said: "Although I was first named the language and mathematical logic smart, but I do not think they are the most important fact, I think the nine intelligent equally important, however, our society today language and mathematical logic smart set. In the most important position on the most intelligent tests are built on this basis. If you are good at math and language, your IQ tests and SAT (Scholastic aptitude test) scores must be very high, so you can enter the prestigious universities. But once you leave school, whether there is still a good performance, often to a large extent depends on whether you have a number of intelligence and the ability to use addition. I have given the same attention intelligence, language and mathematical logic it is outside. "And musical / rhythmic intelligence is precisely the one in which Gardner give equal attention intelligent. Musical / rhythmic intelligence: refers to the personal feelings, discrimination, memory and ability to express the music, the performance of individual rhythm, tone, timbre and melody sensitive and by composing, playing, singing and other forms to express their own thoughts or feelings.

Musical / rhythmic intelligence development and training is the main way of music education, music primarily through tone (from the development trend of modern music, the voice of all nature, whether musical or noise, just give it some kind of performance factors, can become musical elements), organized by virtue of acoustic vibrations exist, and in time to show the incoming artistic variety of emotional responses and emotional experience caused by our auditory organ. Through music education, you can use the music to reflect the social practice of human labor, the performance of the human spirit, reflecting the understanding of real life, showing people a new life in the pursuit of ideals and vision. Bear passing emotional, social organization and coordination of information and members of the community will conduct other tasks. In short, the music is longer than the performance of the spiritual world and the spiritual world through the show reveals the material world. This is the other art forms can not be replaced characteristics. The second is to educate people through music, which is the ultimate goal of music education - Music Education Educational Value. That culture needs the comprehensive development of society with full human dignity. It is in the promotion of personality development, promote human subjectivity, the emotional effect, the aesthetic effect and the development of human potential wisdom, education value in terms of the formation of the human spirit and so embodied. "Music education is not cultured musicians, but the first cultured people." Famous American composer, educator Dr. also said: "Learning music is not only for art, for entertainment, but to train the mind, physical and mental development, in this regard, music is very important." At this point, the fundamental purpose of music education and quality of education is the same.

\section{The Theory of Multiple Intelligences}

Structure theory of multiple intelligences is mainly from the United States over the development. The theory by the American educator, psychologist Gardner in the late 20th century made an important theory of intellectual development. Structure of Multiple Intelligences theory believes that intelligence is not a single individual, which is actually a diverse structure. Gardner in the course of the study in himself as an example, there are eight and a half consider themselves intelligent. Thus Gardner believes that everyone has a different more or less intelligent half, due to the intelligent combination of different, and thus the extent of the role is not the same, but after the latter part of 
education and training will be able to play a higher level. Thus, Gardner's basic education in the course of conducting educational activities should be fully developed in every human brain intelligence on the different options based on the educated, so that educators in the process of education can play to their strengths, their potential intelligence inspire them to play their own personality. Theory of Multiple Intelligences structure generally includes nine content areas. The first is linguistic intelligence, that is, people with the ability to master the use of language. The second is the logical intelligence, that is, people understand the logical structure of the relationship, reasoning, thinking skills. The third is the visual intelligence. That is, people of color, shape, space, location and expression of feelings of capability. The fourth is a musical intelligence. The fifth movement is intelligent. The sixth is interpersonal intelligence. That is more sensitive to others facial expressions, gestures and talk to make response. The seventh is a smart self-reflection. That is self-understanding, insight and self-reflection capabilities. The eighth is the naturalist intelligence. People identify biological and other features of the natural world and the sensitive capacity. The final step is the presence of intelligence. As presented, thinking about life and death, physical and mental abilities.

\section{The Educational Value of Music Education Based on Multiple Intelligences}

From the foregoing discussion of the theory of multiple intelligences structure can be found in the way of thinking and understanding of things is the diversity of the human brain, a single individual there is a wide range of potential intelligence. By structure theory of multiple intelligences can be found, musical intelligence is an intelligent every individual has the. On this layer of meaning we can fully understand that music is not only a small part in order to learn, anyone can use a variety of ways to learn music. Musical intelligence is a concrete manifestation of people's intelligence. Musical intelligence can be reflected in the life of all types of people, each person who will be able to reflect their own unique musical intelligence. For this special group of ordinary people, music can not give it the same life force. Educators in the course of conducting educational activities in music education can not only affect people's ability to enjoy music, but also can affect a variety of related intelligence activities in music education, music for a number of intelligent people have a certain impact on the development of effect. After education practice shows that students in the learning process if you can accept the music courses of study, math and language scores were significantly higher than did not receive music courses for students. At the same time, the longer the time for students to learn music, their language and math achievement shorter than music students learn better. From this, music education activities for students to improve language and logic, intelligence has a certain role in promoting.

At the same time, relevant education researchers also pointed out that the presence of the value of music and music education in the process of learning music can improve the experience of self-awareness and emotional effect. People in the process of learning music may be another way to express their inner feelings, in this way music affects people's development. Not only can develop people's musical intelligence, but also to promote the development of related intelligence. As we all know that, from a certain sense, the music needs to be expressed through language, people express their feelings in the process, it is possible to communicate through language and music. In language, tone and temperament have a certain understanding and people can use music to express their feelings. The music and dance itself has close links, dance has important implications for the development of smart people to exercise. In the grasp of melody in the process can be improved logic intelligence. The art form of music has an important influence on the development of visual space and people's creativity. In the process of music education, music can affect people in many aspects of intelligence, improve the people's intelligence. Thus, in the perspective of the theory of multiple intelligences structure, education value of music education can not be ignored. In the process of education personnel to carry out educational activities, the role of music education into full play, will contribute to the development of the educated.

Based on the theory of multiple intelligences Gardner's structure, on the one hand in the development of music education and training of individual intelligence reflects the unique value, that 
is, in real life, people do not rely on a certain kind of intelligence but need to use a combination of multiple intelligence a comprehensive solution to the problem. This means that the value of music education is reflected in the development and training through direct individual musical / rhythmic intelligence, making multiple intelligence structure is an important part of human society to solve various specific practical problems. Music education can on the other hand, directly or indirectly, explicitly or implicitly to develop and train human speech / linguistic intelligence, logical / mathematical intelligence, visual / spatial intelligence, musical / rhythmic intelligence, bodily / kinesthetic intelligence, interpersonal intelligence, self-reflection smart, intelligent observer of nature, the presence of other nine intelligent integrated intelligence. So that they mutually penetrate each other, mutual influence, interaction, so as to lay a solid foundation for culture overall quality of students.

\section{Conclusion:}

In short, the process of implementation of quality education, educators should be educating people the value of music education adequately reflected. Music education can encourage people to develop multiple intelligences. While in the process of education can also take advantage of multiple intelligence structure to promote the development of music education, to ensure that fully reflects the value of education.

\section{References}

[1] B. N. Ma, The diversification of higher education mode of art, J. Higher Education Research. 44 (2012) 146-147.

[2] H.X.Zeng, The university art education and on the overall quality of human capacity, J. China Educational Technology Equipment. 18(2015) 55-57.

[3] J.H.Xue, The professional ability standards of engineering higher artistic education pluralistic value, J. China Electric Power Education, 32(2013) 189-190.

[4] Y.J.Qi, G Multiple intelligences and learning strategies, J, Artistic Renditions, 4(2013) 38-40.

[5] Y.M.Tian, Multi - value of arts education, J. China Electric Power Education, 9(2013) 142-150. 